\title{
A STUDY ON DETERMINANTS OF IMMUNIZATION COVERAGE AMONG 12-23 MONTHS OLD CHILDREN IN URBAN SLUMS OF LUCKNOW DISTRICT, INDIA
}

BHOLA NATH, J. V. SINGH, SHALLY AWASTHI*, VIDYA BHUSHAN, VISHWAJEET KUMAR ${ }^{\star \star}$, S. K. SINGH

\section{ABSTRACT}

CONTEXT: To find out the suitable factors for raising the coverage of immunization. AIMS: To determine the coverage and to identify the various factors of primary immunization. SETTINGS AND DESIGN: Urban slums of Lucknow district. METHODS AND MATERIAL: WHO 30-cluster sampling technique was used for the selection of the subjects. Mother, father or relative of a total of 510 children with 17 children per cluster were interviewed in the study. STATISTICAL ANALYSIS: Chi-square test, binary logistic regression and multinomial logistic regression analysis were done to test the statistical significance of the association. RESULTS: About $44 \%$ of the children studied were fully immunized. Multinomial logistic regression analysis revealed that an illiterate mother $(O R=4.0)$, Muslim religion $(O R=2.5)$, scheduled caste or tribes $(O R=2.3)$ and higher birth order $(O R \approx 2)$ were significant independent predictors of the partial immunized status of the child; while those associated with the unimmunized status of the child were low socioeconomic status $(O R=10.8)$, Muslim religion $(O R=4.3)$, higher birth order $(O R=4.3)$, home delivery $(O R=3.6)$ and belonging to a joint family $(O R=2.1)$. CONCLUSIONS: The status of complete immunization is about half of what was proposed to be achieved under the Universal Immunization Program. This emphasizes the imperative need for urgent intervention to address the issues of both dropout and lack of access, which are mainly responsible for partial immunization and nonimmunization respectively.

Key words: Coverage evaluation, dropout, primary immunization

Immunization has been one of the most significant, cost-effective and stimulatory public health interventions. India, along with the whole world, stands committed to the welfare of children, as reflected in the theme of 'World Health Day, 2005,' viz., 'Make every mother and

Departments of Community Medicine, *Pediatrics, King George's Medical University, **Project Director, KGMU-JHU Collaborative projects, Lucknow, India

\section{Correspondence:}

Dr. Bhola Nath, 124 A/ 186, Block No.11, Govind Nagar, Kanpur, Uttar Pradesh - 208 006, India. E-mail: bhola_2001 @sify.com child count.'[1] The most important indicators mentioned in the Millennium Development Goals (MDGs) are the under-5 mortality rate (U5MR), infant mortality rate (IMR) and proportion of 1-year-old children immunized against measles (P1MV). About one-quarter, or $25 \%$, of under- 5 mortality is due to vaccinepreventable diseases. ${ }^{[2]}$

The World Health Organization (WHO) launched the Expanded Program on Immunization (EPI) in 1974 globally with focus on prevention of the 
six childhood vaccine-preventable diseases by the year 2000 . This was endorsed by the Government of India in 1978. ${ }^{[3]}$ Later, on November 19, 1985, the Universal Immunization Program (UIP) was introduced in India with the objective to cover at least $85 \%$ of all infants by $1990 .{ }^{[4]}$ Further, a national socio-demographic goal was set up in National Population Policy (NPP) 2000 - to achieve universal immunization of children against all vaccine-preventable diseases by $2010 .{ }^{[5]}$

In the last 50 years, India's population grew two and one-half times, but urban India grew nearly five times. ${ }^{[6]}$ Most of this growth is due to migration, leading to mushrooming of slums. With the rapid growth of big cities, an impending threat of outbreak of vaccinepreventable diseases always exists due to the high population density, continuous influx of a new pool of infective agents with the immigrating population and poor coverage of primary immunization in the urban slums. ${ }^{[7,8]}$ In view of this, it is necessary to understand the dynamics of utilization of immunization services by the community. Hence the present study was undertaken to find out the various reasons responsible for the suboptimal coverage of immunization in the urban slums of Lucknow, a centrally placed district of the most populous Indian state, Uttar Pradesh, ${ }^{[9]}$ with $14.4 \%$, i.e., 5.2 lakhs (according to Urban RCH 2000), of its population residing in the slums. A vaccination coverage study conducted in this district in 1992 found only 1 in 6 children to have been completely immunized. ${ }^{[10]}$ The current study seeks to determine whether the situation has improved since and to more fully identify risk groups and reasons for under-immunization.

\section{MATERIALS AND METHODS}

A coverage evaluation survey was done from January 2005 to April 2005 among children aged 12-23 months in the urban slums of Lucknow district, using the WHO 30-cluster survey methodology. ${ }^{[11]}$ It is a kind of two-stage sampling technique where 30 slums from the district were randomly selected in the first stage according to 'Probability Proportion to Size (PPS),' which ascertains that the probability of a particular sampling unit being selected in the sample is proportional to the population size of the sampling unit. ${ }^{[12]}$ In the second stage, the selection of the required number of children was done from each of the selected clusters. The first child in each cluster was selected randomly, and the rest of them were selected from the contiguous households till the required number of children was attained. O

The total number of children studied was 510 , with 17 children in each cluster $\{P=0.21$ (proportion of fully immunized children aged 12-23 months in Uttar Pradesh, according to National Family Health Survey-2 ${ }^{[13]}$ (NFHS-2), confidence limit $=95 \%$, absolute precision (d) $=5 \%$, design effect $\left.=2^{[14]}\right\}$. To find 510 eligible children, we surveyed a total of 3,840 households. In the houses having twins, only one of them was selected randomly. Only those respondents who were residing in the area for the last 6 months or more were included in the study.

A pre-tested structured questionnaire was used to elicit the information from the study participants. Information was collected on the various socio-demographic factors, about the immunization status and reasons for partial immunization and nonimmunization of the children. The method used for the determination of the vaccination status was 'the vaccination card and the recall' method. The primary respondent was the mother of the child; and in case of her absence, the father acted as the next respondent. In case of absence of both of them, an adult in the household who remained with the child for most of the time or had taken the child for immunization on at least one occasion was interviewed.

The child was considered as 'fully immunized' if he/ she had received one dose each of BCG and measles and three doses each of DPT and polio (excluding Polio 0 dose) by his/ her first birthday. Those who had missed any one vaccine out of the six primary vaccines were described as 'partially immunized,' and those children who had not received any vaccine up to 12 months of age were defined as 'unimmunized. [15] The 'overall dropout rate' was the percentage point difference between the vaccines of the maximum and the minimum antigen received, expressed as a percentage of the maximum dose.

Statistical analysis was done by using the software SPSS 10.0.1 for Windows. A p-value of $<0.05$ was considered significant. Univariate linear regression and multinomial logistic regression analyses were performed with immunization status as the dependent variable and the risk factors as independent variables. Multinomial logistic regression analysis was used because it attempts to remove the confounding effect of the independent variables on each other and thus finds out the independent association of each independent variable with the dependent one.

\section{RESULTS}

In the 30 clusters, a total of 3,840 households were surveyed to find the 510 eligible subjects. It was observed that $47.2 \%$ of the total number of children, complete and partially immunized, had vaccination cards. Also, though the immunization program reached to about $76 \%$ of the target children, only about $44.1 \%$ of the children received all the vaccines. The proportion of children with no immunization at all was about $24 \%$ [Table 1].

The 'overall dropout rate' was quite high, with one in three children being not able to complete the course of vaccination [Table 2].

The commonest reason for the partia immunization of the child according to the respondents was the unavailability of both the parents (17.2\%). Another major reason for partia immunization was that parents had gone eithe to village/ native place during the scheduled date of vaccine or had been residing in the area for more than 6 months but had not yet acquired the necessary information regarding the details of vaccine administration (14.7\%) and thus missed the dose of the vaccine. This was followed by carelessness $(11.7 \%)$, sickness of elder sibling as a result of the vaccination (11.7\%) and lack of knowledge regarding the subsequent vaccination

Table 1: Distribution of children according to their immunization status in Lucknow district, India, 2005

\begin{tabular}{lcc}
\hline Immunization status & Number $(\mathrm{N}=510)$ & $\begin{array}{c}\text { Percentage } \\
(95 \% \mathrm{Cl})\end{array}$ \\
\hline Fully immunized & 225 & 44.1 \\
Partially immunized & 163 & $(37.9-50.5)$ \\
& & 32.0 \\
Unimmunized & 122 & $(26.4-38.1)$ \\
& & 23.9 \\
& & $(18.9-29.7)$ \\
\hline
\end{tabular}


Table 2: Dropout rates according to vaccines amongst children in Lucknow district, India, 2005

\begin{tabular}{lccc}
\hline Vaccines & & Dropped out of & Percentage \\
\hline DPT/OPV* & I to II dose & $35 / 367$ & 9.53 \\
& II t III dose & $50 / 332$ & 15.06 \\
& I to III dose & $85 / 367$ & 23.16 \\
DPT III - Measles & & $37 / 282$ & 13.12 \\
Overall Drop-out rate & $122 / 367$ & 33.24 \\
\hline${ }^{*}$ Diphtheria, pertussis and tetanus vaccine/ oral polio vaccine & &
\end{tabular}

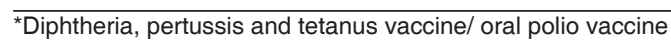

(10.4\%). On the other hand, about $36.1 \%$ of the respondents of the unimmunized children considered that Polio vaccine (during the Pulse Polio Initiative) was the only vaccination to be given. Another $23.8 \%$ had lack of knowledge about the vaccination, while 16.4 and $14.8 \%$ had lack of faith on its effectiveness and were apprehensive due to the sickness of elder sibling respectively [Table 3]

It was observed through the binary logistic regression analysis that lack of faith, lack of knowledge and considering polio as the only vaccine were significant independent reasons for nonimmunization of the child according to the respondents [Table 4].

$$
\text { out thes }
$$

To find out the significant independent predictors of partial immunization of the child, multinomia

Table 3: Reasons for partial immunization and nonimmunization of the children according to the respondents in Lucknow district, India, 2005

\begin{tabular}{|c|c|c|c|c|}
\hline \multirow[t]{2}{*}{ Reason } & \multicolumn{2}{|c|}{$\begin{array}{c}\text { Partially immunized }{ }^{*} \\
(N 2=163)\end{array}$} & \multicolumn{2}{|c|}{$\begin{array}{l}\text { Unimmunized }{ }^{*} \\
(\mathrm{~N} 3=122)\end{array}$} \\
\hline & No. & $\%$ & No. & $\%$ \\
\hline Both the parents were bc & 28 & 17.2 & 4 & 3.3 \\
\hline Went to village/ native place/migrated to other place & 24 & 14.7 & 0 & 0 \\
\hline Child/sibling became ill as a result of previous vaccination & 19 & 11.7 & 18 & 14.8 \\
\hline Carelessness & 19 & 11.7 & 4 & 3.3 \\
\hline No knowledge of vaccine and /or place & 17 & 10.4 & 29 & 23.8 \\
\hline No reason & 17 & 10.4 & 7 & 5.8 \\
\hline Child was ill and not brough & 14 & 8.6 & 0 & \\
\hline Mother was ill & 13 & 8.0 & 0 & 0 \\
\hline Mother was too busy & 12 & 7.4 & 0 & 0 \\
\hline Child was brought but because of illness not given immunization & 10 & 6.1 & 0 & 0 \\
\hline Opposition from family members & 7 & 4.3 & 2 & 1.6 \\
\hline No one came at home & 6 & 3.7 & 15 & 12.3 \\
\hline Financial constraints & 3 & 1.8 & 2 & 1.6 \\
\hline Fear of side reactions & 3 & 1.8 & 6 & 4.9 \\
\hline No faith & 3 & 1.8 & 20 & 16.4 \\
\hline Father too busy & 2 & 1.2 & 1 & 0.8 \\
\hline Husband not willing & 2 & 1.2 & 2 & 1.6 \\
\hline Polio was considered as the only vaccination to & 1 & 0.6 & 44 & 36.1 \\
\hline Others & 8 & 4.9 & 5 & 4.1 \\
\hline
\end{tabular}

Others

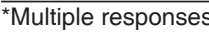

Table 4: Binary logistic regression analysis of reasons as told by the respondents for nonimmunization of the child in Lucknow district, India, 2005

\begin{tabular}{|c|c|c|c|c|}
\hline \multirow[t]{2}{*}{ Reasons } & \multicolumn{2}{|c|}{ Odds ratio (OR) } & \multicolumn{2}{|c|}{$\begin{array}{l}95 \% \text { confidence interval } \\
\text { (Cl) for adjusted OR }\end{array}$} \\
\hline & Unadjusted & Adjusted & Lower & Upper \\
\hline No faith & 10.5 & 23.7 & 6.7 & 84.4 \\
\hline No knowledge of vaccine and /or place & 2.7 & 4.6 & 2.2 & 9.6 \\
\hline Polio (only vaccine) & 91.4 & 137.6 & 18.4 & 1030.6 \\
\hline
\end{tabular}

logistic regression analysis was done, which revealed that a child with an illiterate mother had about four times greater chance of being partially immunized than that with 'XII class'passed mother. Also, Muslim religion ( $\mathrm{OR}=2.5$ ), belonging to scheduled caste or tribes (OR=2.3) and higher birth order $(O R \approx 2)$ were found to have significant independent association with partial immunization [Table 5].

Similarly, a search for independent predictors of unimmunized status of the child led us to the conclusion that low socioeconomic status $(O R=10.8)$, Muslim religion $(O R=4.3)$, higher birth order $(\mathrm{OR}=4.3)$, delivery at home $(O R=3.6)$ and belonging to a joint family $(\mathrm{OR}=2.1)$ increased the risk of nonimmunization significantly. Surprisingly, the literacy status of the mother had no significant independent bearing on the unimmunized status of the child [Table 5].

\section{DISCUSSION}

We have tried to bring out the specific factors responsible for partial immunization and

$$
\text { for partial immuni }
$$

Table 5: Multinomial logistic regression analysis of predictors of partial and unimmunized status of childre

\begin{tabular}{|c|c|c|c|c|c|c|}
\hline \multirow[t]{2}{*}{ Predictor } & \multirow{2}{*}{$\begin{array}{c}\text { Immunization status } \\
\text { of the children }\end{array}$} & \multirow[t]{2}{*}{$\beta$ coeff } & \multicolumn{2}{|c|}{ Odds ratio } & \multirow{2}{*}{$\begin{array}{c}95 \% C I^{*} \text { for } \\
\text { adjusted OR }\end{array}$} & \multirow[t]{2}{*}{$P$-valuet } \\
\hline & & & Unadjusted & Adjusted & & \\
\hline \multirow{4}{*}{$\begin{array}{l}\text { Mother's education (more than } \\
\text { XII }=0 \text {, upto } \mathrm{XII}=1 \text {, Illiterate }=2 \text { ) } \\
\text { Religion (Hindu }=0, \text { Muslim }=1 \text { ) }\end{array}$} & Partially immunized & 1.390 & 9.4 & 4.0 & $1.4-11.4$ & $0.009^{*}$ \\
\hline & Unimmunized & 0.872 & 75.1 & 2.4 & $0.2-30.5$ & 0.502 \\
\hline & Partially immunized & 0.930 & 2.7 & 2.5 & $1.4-4.5$ & $0.001^{*}$ \\
\hline & Unimmunized & 1.459 & 6.8 & 4.3 & $2.2-8.3$ & $0.000^{*}$ \\
\hline \multirow[t]{2}{*}{ Caste (Gen. $=0, \mathrm{OBC}=1, \mathrm{SC} / \mathrm{ST}=2$ ) } & Partially immunized & 0.853 & 3.9 & 2.3 & $1.2-4.6$ & $0.014^{*}$ \\
\hline & Unimmunized & 0.738 & 8.7 & 2.1 & $0.8-5.6$ & 0.139 \\
\hline Birth order $\left(1^{\mathrm{s}}=0,2^{\text {nd }}=1\right)$ & Partially immunized & 0.736 & 2.5 & 2.1 & $1.1-3.8$ & $0.017^{*}$ \\
\hline \multirow{4}{*}{$\begin{array}{l}\text { Birth order }\left(1^{\mathrm{t}}=0,3^{\mathrm{dd}}=2\right) \\
\text { Birth order }\left(\left(^{1 \mathrm{t}}=0,2^{\mathrm{dn}=}=1,3^{\mathrm{dd}}=2\right)\right. \\
\text { Type of family (Nuclear=0, Joint=1) }\end{array}$} & Partially immunized & 0.638 & 4 & 1.9 & $1.0-3.4$ & $0.033^{*}$ \\
\hline & Unimmunized & 1.471 & 15.8 & 4.3 & $1.8-10.4$ & $0.001^{*}$ \\
\hline & Partially immunized & 0.201 & 2.0 & 1.2 & & 0.409 \\
\hline & Unimmunized & 0.735 & 5.6 & 2.1 & $1.0-4.1$ & $0.036^{*}$ \\
\hline \multirow{4}{*}{$\begin{array}{l}\text { Socioeconomic status } \\
\text { (Upper class }=0 \text {, Lower class=1) } \\
\text { Place of delivery } \\
\text { (Institutional }=0 \text {, Home=1,) }\end{array}$} & Partially immunized & 0.143 & 0.2 & 1.2 & $0.6-2.2$ & \\
\hline & Unimmunized & 2.379 & 188.7 & 10.8 & $1.1-107.4$ & $0.042^{*}$ \\
\hline & Partially immunized & -.306 & 1.5 & 0.7 & $0.4-1.2$ & 0.222 \\
\hline & Unimmunized & 1.293 & 10.7 & 3.6 & $1.8-7.2$ & $0.000^{*}$ \\
\hline
\end{tabular}
in Lucknow district, India, 2005

Indian J Med Sci, Vol. 61, No. 11, November 2007 nonimmunization as compared to simila previous studies, so that solutions can be tailored specifically to the individual groups on the basis of evidence, rather than using a common-sense approach.

Our study revealed that a significan improvement in the percentage of complete immunization has occurred, from $16.2 \%$ in $1992^{[10]}$ to $44.1 \%$ in 2005 , in the urban slums of Lucknow district, as a result of sustained efforts by the government; but the achievements lag far behind the national goal, even after more than 20 years of formal introduction of the UIP. Other studies in urban slums of Delhi[ ${ }^{[16]}(69.3 \%)$ and Chandigarh ${ }^{[17]}(58.6 \%)$ report a higher but suboptimal coverage. However, these studies WHO 30-cluster survey methodology and thus had different results.

The dropout rate for I to III doses of DPT in the urban slums of Lucknow has also decreased from $28 \%$ in $1992^{[10]}$ to $23 \%$ but is still quite high, with the overall dropout rate being an overwhelming $33 \%$. The dropout rates of 16 had used a different methodology instead of the 
and $21 \%$ for DPT and Polio respectively in NFHS-2 ${ }^{[18]}$ were comparable to our study. The problem of dropout has different program-related implications as compared to the unimmunized group. It reflects lacunae in the health system and the opportunities missed. According to the respondents, the commonest reason for the partial immunization of the child was the unavailability of both the parents $(17.2 \%)$ to fulfill the child's health needs, as they were preoccupied in the livelihood-generation activities. This reflects the un-met needs of the community, which require organization of outreach services on fixed date and timing with prior information to the locality. Other reasons for partial immunization were missing of the dose due to the visit to the native place/ village $(14.7 \%)$ compared to $23.1 \%$ in the study done by Malini Kar et al., ${ }^{[16]}$ carelessness $(11.7 \%)$, apprehensiveness due to sickness of the child or an elder sibling as a result of vaccination $(11.7 \%)$ and lack of knowledge ( $10.4 \%$ vs. $23.1 \%$ by Malini Kar et al. ${ }^{[16]}$ ). Solving these would require proper education and constant motivation through an encouraging and persuasive interpersonal approach, regular reminders and removal of misconceptions prevailing among people and improving the quality of the services at the health facility, along with proper training of the health provider to seize the 'missed opportunities. ' $[19,20]$

About $36 \%$ of the unimmunized respondents thought that the pulse polio was the only vaccine that needs to be given. Interviews with the field staff in the past have also revealed that low immunization coverage was partly due to emphasis given to Pulse Polio Initiative (PPI) as compared to routine immunization services. ${ }^{[2]}$ We need to develop strategies to prevent the overshadowing of other VPDs due to PPI. Another $23.8 \%$ had lack of knowledge about the vaccination, while $16.4 \%$ had lack of faith on its effectiveness. The study in the urban slums of Delhi found the corresponding percentages to be 64 and $16 \%$ respectively. ${ }^{[16]}$ The best approach to ensure a consistent coverage of all the vaccines would be to generate the demand regarding immunization services through interpersonal communication and motivation.

Children born at home were found to be less likely to receive any vaccination. This is particularly important in the light of the fact that domiciliary deliveries in UP and Rajasthan are one of the highest in the country. ${ }^{[21]}$ Mothers who deliver at home may be non-users of health services in general and have to be targeted for utilization of health services. The presence of the high birth order and home delivery as independent predictors of nonimmunization emphasizes the need to broaden our focus from the infants to the pregnant females as well, to ensure the safety of the child against the six deadly but preventable diseases.

The intervention programs need to be tailored specifically for the Muslim community and those belonging to the low socioeconomic status through an in-depth analysis of the psychosocial needs and subsequent corrective actions. NFHS-2 ${ }^{[13]}$ has also presented similar results with respect to the risk associated with the Muslim religion, literacy status of the mothers and scheduled caste/ tribes. A joint family was twice at risk of having an unimmunized child as compared to a nuclear family and therefore should be addressed through involvement of decision makers like father, mother-in-law, in addition to the mother; and anti-vaccine rumors need to be countered. ${ }^{[22]}$ The caste of the child and, surprisingly, mother's literacy status did not significantly predict unimmunized status of the child in the absence of confounding factors. These results are also consistent with those of the study by Malini Kar et al. ${ }^{[16]}$ This emphasizes the fact that if the social mobilization activities are properly implemented, they can have a significant impact in changing the attitude of the people irrespective of the caste or the educational qualification of the mother.

The study also revealed that place of delivery did not have an independent bearing on the partialimmunized status of the child. This was probably because institutional deliveries may have a bearing on administration of initial vaccines but not for the subsequent vaccines, in the absence of proper motivation. Similarly, socioeconomic status had no independent association with partial immunization, probably because the immunization services are accessible and affordable to all the people irrespective of their socioeconomic status. Illiteracy of the mother was significantly associated with partial immunization, and this has also been documented in other studies. ${ }^{[18,22-25]}$

\section{Strengths}

According to the WHO cluster-survey methodology, which is the gold standard for the coverage evaluation survey, the required sample size usually taken is 210 ; but we had taken an absolute precision of $5 \%$ instead of $10 \%$ and a prevalence of $21 \%$ as compared to $50 \%$ to achieve a sufficiently large sample size to increase the precision. The study done in 1992 by R. Chandra et al. ${ }^{[10]}$ was conducted with a similar methodology in the urban slums of Lucknow district but had a sample size of only 210 . Therefore, the results of our study are more precise as compared to those of the study by R. Chandra et al. Moreover, the study did not try to bring out the determinants of low immunization coverage and thus we lack data for comparison of our findings. We excluded the respondents who were residing in the area for less than 6 months to avoid the bias regarding their knowledge and practices in a new place.

\section{Limitations}

The results revealed a prevalence of $44 \%$ of fully immunized children as compared to $21 \%$, which was the prevalence that was available at the time of sample size calculation. A prevalence of $44 \%$ would provide us a precision of $\pm 6 \%$ as compared to the $\pm 5 \%$ that we had allowed in our study, thus increasing the range of the values that we have obtained. We tried our best to minimize the recall bias by confirming and reconfirming the immunization status by enquiring about the various aspects of the vaccine, such as name, site and age of administration; but as it is with any othe study, it could not be totally eliminated. We could also not study the inadequacies related to the health care delivery aspects, which have also been found to be responsible for the low immunization coverage, due to the paucity of resources.

\section{CONCLUSIONS}

The goal of achieving universal immunization especially in the disadvantaged, vulnerable urban slum population with poor health infrastructure, needs a coordinated effort and a multi-pronged strategy to deal with both lack 
of access and dropout. The measures to be taken would include reaching out effectively to people to generate demand for the services through interpersonal communication, which can be translated into a change in behavior, and then maintaining the demand consistently. Involvement of private agencies and other stakeholders may lead to the much-needed political, civil-society and media pressure and periodic uproar on the issue.

\section{ACKNOWLEDGEMENT}

We thank the respondents for taking part in the interview and sharing their experiences. Our special thanks to Dr. Ranjeeta who helped and provided constant comfort during the course of this study.

\section{REFERENCES}

1. World Health Report, 2005. Available from: http:// www.who.int/whr/2005/en/index.html.

2. Kalaivani K, Mathiyazhagan T, Patro BC. Editorial. News Lett Nat Inst HIth Fam Welfare 2006;8:12.

8. Loening WE, Coovadia HM. Age specific occurrence rates of measles in urban, peri-urban and rural environment: Implications for time of vaccination. Lancet 1983;2:324-6.

9. Census of India, 2001. Available from: http://www. censusindia.net/results/prov india1.html.

10. Chandra R, Srivastava VK, Nirupam S. Impact of urban basic services on immunization coverage in a slum area of Northern India. Asia Pac J Public Health 1992-1993;6:153-5.

11. Henderson RH, Sundaresan T. Cluster sampling to assess immunisation coverage: A review of experience with a simplified sample method. Bull World Health Organ 1982;60:253-60.

12. Probability proportional to size, Cluster Sampling CDC. Available from: http://www.cdc.gov/cogh/ descd/modules/Minimodules/PPS/page02.htm.

13. Mortality, Morbidity and Immunization in UP. National Family Health Survey-2, Uttar Pradesh; 1998-99. p. 137.

14. Lwanga SK, Lemeshow S. Sample size determination in Health studies: A practical manual. WHO: Geneva; 1991. p. 1

15. Evaluate Service Coverage, Ministry of Health and Family welfare, Government of India, New Delhi; 1992.

16. Malini Kar, Reddaiah VP, Kant S. Primary immunization status of children in slums areas of South Delhi: The challenge of reaching Urban Poor. Indian J Community Med 2001;26:151-4.

17. Bhatia V, Swami HM, Rai SR, Gulati S, Verma A, Parashar A, et al. Immunization status in children. Indian J Pediatr 2004;71:313-5.

18. Mortality, Morbidity and Immunization. National Family Health Survey (NFHS-2). India; 19981999. p. 205-8.

19. Mukherjee B, Ray SK, Kar M, Mandal A, Mitra J, Biswas R. Coverage evaluation surveys amongst children in some blocks of West Bengal. Indian J Public Health 1990;34:209-14.

20. Bhattacharjee J, Singh J, Sharma RS. Reasons for immunization failure in infants of North India. Indian J Community Med 1993;18:160-3.
21. EHP -USAID, 2003. Standard of living index based reanalysis of National Family Health Survey (NFHS-2), India and state reports 1998- 1999 International institute of population sciences (IIPS) and ORC - Macro: Mumbai; 2001.

22. Singh $P$, Yadav RJ. Immunization status of children of India. Indian Pediatr 2000;37:1194-9.

23. Suresh K, Saxena D. Trends and determinants of immunization coverage in India. J Indian Med Assoc 2000;98:10-4.

24. Perry $\mathrm{H}$, Weierbach R, Hossain I, Islam R.
Childhood immunization coverage in Zone 3 of Dhaka city: The challenge of reaching impoverished households in urban Bangladesh. Bull World Health Organ 1998;76:565-73.

25. Luman ET, McCauley MM, Shefer A, Chu SY. Maternal characteristics associated with vaccination of young children. Pediatrics 2003;111:1215-8.

Source of Support: Nil, Conflict of Interest: None declared. 